\title{
Anarquismo Ontológico e Verdade no Antropoceno
}

\author{
Mauro W. B. Almeidal \\ ${ }^{1}$ Universidade Estadual de Campinas, São Paulo, SP, Brasil
}

\section{Resumo}

Há um problema central na filosofia das ciências e que tem implicações importantes para a antropologia e sua aliança com cientistas naturais contra o aquecimento global, as pandemias e a perda de biodiversidade. O problema é: como afirmar essa coalização reconhecendo a existência desses fenômenos e, ao mesmo tempo, defender a autonomia ontológico de diferentes povos? Minha resposta, sem pretensão de originalidade, é que o critério de verdade pragmática torna possível estabelecer cabeças de ponte que conectam múltiplos mundos, sem deixar de reconhecer a incomensurabilidade ontológica que os distingue.

Palavras-chave: Antropoceno. Conflitos Ontológicos. Verdade Pragmática.

\section{Ontological Anarchism and Truth in the Anthropocene}

\begin{abstract}
There is a central problem in the philosophy of science and it has important implications for anthropology and its alliance with natural scientists against global warming, pandemics and loss of biodiversity. The problem is: how to affirm this coalition recognizing the existence of these phenomena, and at the same time defend the ontological autonomy of different peoples? My answer, without pretending to be original, is that the criterion of pragmatic truth makes it possible to establish bridgeheads that connect multiple worlds, while recognizing the ontological immeasurability that distinguishes them.
\end{abstract}

Keywords: Anthropocene. Ontological Conflicts. Pragmatic Truth. 


\section{Conflitos Ontológicos e Verdade Pragmática}

$\mathrm{C}$

omo afirmar, ao mesmo tempo, a realidade do aquecimento global e da pandemia planetária e a autonomia ontológica dos povos? A resposta é que é possível admitir as duas posições: o reconhecimento da verdade do consenso científico e a multiplicidade de mundos irredutíveis entre si. O senso comum já indica que há cabeças de ponte entre povos dotados de metafísicas radicalmente diferentes. Um exemplo disso é que os chamados povos isolados da Amazônia extraem de seus vizinhos "civilizados" facas e machados para usar como "coisa-para-cortar" - concordando, assim, pragmaticamente com seus vizinhos ${ }^{1}$.

A antropologia das ciências enfrenta hoje em dia um cabo de guerra que a puxa em duas direções opostas: de um lado, o relativismo cultural, e, do outro lado, o naturalismo científico $^{2}$. Esse cabo de guerra tem implicações políticas cruciais, porque o relativismo cultural tem sido manipulado para justificar a ausência de diferença entre fake news e verdade, sendo assim possível afirmar que podemos aceitar ou rejeitar a existência de aquecimento global, de pandemias e de erosão da biodiversidade como visões igualmente sustentáveis, sem que haja critérios que permitam distinguir a verdade da falsidade dessas posições, bem como a racionalidade ou a falácia dos argumentos envolvidos. Em contraposição ao relativismo cultural, o naturalismo científico, visto como ontologia de cientistas naturais, afirma a existência do aquecimento global, de pandemias e da degradação de organizações sociais.

A pergunta é: como justificar a aliança entre antropólogos contra fenômenos globais, como o aquecimento global, pandemias planetárias e a erosão da diversidade biológica e social, preservando a defesa da autonomia ontológica de terranos?

Há uma resposta a esse dilema que preserva a missão da antropologia como ciência da autodeterminação ontológica dos povos do mundo (VIVEIROS DE CASTRO, 2003), e, ao mesmo tempo, justifica a adesão ao consenso científico a respeito da origem antrópica da catástrofe climática (DANOWSKI; VIVEIROS DE CASTRO, 2014). Trata-se de justificar o acordo entre ciências globais e ciências locais sem englobar metafísicas locais como variações de metafísicas globais.

Para Heidegger (2012, p. 211 ss.), facas e machados são pragmata (Zeuge), "trecos" pré-ontológicos por meio dos quais se dá o encontro com o mundo. Ontologias (no plural) são domínios de entes de ciências ou de um modo de vida (HUSSERL, 2007). Conforme aponta Quine (1960), são domínios de referência da linguagem.

2 “Ele tem dois adversários: o primeiro acossa-o por trás, da origem. O segundo bloqueia-lhe o caminho à frente. [...] Seu sonho, porém, é em alguma ocasião, num momento imprevisto [...] saltar fora da linha de combate e ser alçado, por conta de sua experiência de uta, à posição de juiz sobre os adversários que lutam entre si", Franz Kafka, em Arendt (2014, p. 33). 
A solução para esse problema consiste em separar metafísicas e encontros pragmáticos. Pois não se trata de conciliar ou traduzir ciências em conhecimentos locais reduzindo os últimos ao denominador comum do realismo científico. Em vez disso, trata-se de reconhecer que diferentes teorias-cosmologias, ainda que incomensuráveis e irredutíveis entre si, podem dar conta das mesmas experiências - dos mesmos matters of fact - em contextos particulares.

Sob esse ponto de vista, em vez de buscar conciliar ontologias incomensuráveis por meio de reduções simplificadoras e condescendentes - "o que eles querem realmente dizer é que..." - queremos apenas localizar os efeitos pragmáticos das ontologias em questão. O lance de dados da experiência jamais abolirá o acaso ontológico. Ou seja: a experiência pragmática jamais eliminará a multiplicidade metafísica.

Há duas atitudes diferentes. De um lado, o relativismo naturalista admite "representações" reduzidas a fantasmas da realidade objetiva. Por outro lado, a tese da incomensurabilidade ontológica proíbe qualquer sincronização entre regimes de conhecimento, rejeitando traduções como condescendência ontológica (POVINELLI, 2001; ALMEIDA, 2003; 2010). Mas ambas as atitudes bloqueiam a aliança política entre diferentes povos: indígenas, cientistas e filósofos. Isso porque a convocação desses povos à adesão a Gaia parece reconhecer a vitória do monorrealismo ("um mundo composto de vários mundos") como alternativa ao monorrealismo da ciência.

Há uma resposta a esse dilema, que se baseia na distinção entre verdades metafísicas - afirmações que se dirigem a domínios que estão além de qualquer experiência possível - e verdade pragmáticas, que dizem respeito a experiências possíveis. Em segundo lugar, apoia-se na ideia segundo a qual um mesmo núcleo de verdade pragmáticas é compatível com múltiplas verdades metafísicas. Essa distinção significa que múltiplos mundos metafísicos são compatíveis com as mesmas verdades pragmáticas - isto é, com a experiência ${ }^{3}$.

Há, porém, aqui uma paradoxal relação entre relativismo antropológico e empirismo científico. O argumento principal do empirismo é que todo resultado experimental é ontologicamente indeterminado - isto é, há múltiplas ontologias, ou muitos mundos possíveis, compatíveis com a experiência. E essa é também a atitude do relativismo ontológico que estamos afirmando.

A diferença entre a atitude empirista e a atitude antropológica consiste na conclusão retirada dessa constatação. A conclusão empirista é que a ciência deve ater-se aos dados experimentais, já que não pode a partir deles determinar como o mundo realmente é - isto é, não pode determinar a ontologia verdadeira. Para a atitude antropológica, ao contrário, a conclusão é que múltiplas ontologias são compatíveis com os mesmos encontros pragmáticos. Resulta daí a noção de verdades pragmáticas que são comuns a diferentes ontologias (PEIRCE, 1932; 1988; DA COSTA, 1993; 1997).

O aquecimento global, a erosão da biodiversidade, a degradação da diversidade linguístico-cultural e as pandemias planetárias são compatíveis com a termodinâmica e climatologia, biologia, etnografia, biomedicina e a estatística. Ao mesmo tempo, os efeitos pragmáticos esperados por essas ontologias são experimentados por povos como

Essa posição se apoia na minha interpretação da filosofia da ciência de Newton Da Costa e seguidores (DA COSTA, 1993; 1997), sem qualquer autorização por parte do grande filósofo. 
secas e enchentes, fracasso de colheitas, fedor da água, epidemias, e interpretados por meio de outras ontologias. Um exemplo é o diagnóstico de "fome, peste, moda e guerra" como causa do futuro degradado do mundo em cosmologias camponesas nordestinas (ALMEIDA, 1979). E a desordem de ciclos naturais associada à desorientação de animaisprofessores (MESQUITA, 2012; 2013). Todas essas ontologias são compatíveis com as mesmas verdades pragmáticas.

\section{Guerras Ontológicas}

Guerras ontológicas são continuação de guerras materiais. Para justificar a guerra contra sindicatos e a destruição das comunidades de mineiros na Inglaterra, Margaret Thatcher afirmou celebremente que "sociedade não existe"; como nas guerras de religião que visavam eliminar crentes para eliminar seus entes, Thatcher visou a eliminação ontológica da classe de trabalhadores de minas para justificar sua destruição de fato.

No Brasil, grileiros e agronegocistas travam uma guerra para expulsar indígenas, quilombolas e comunidades tradicionais de terras historicamente ocupadas - guerra na qual a violência e a grilagem são acompanhadas pela guerra ontológica, que consiste na negação da existência de tais entes. A truculência física tem continuidade na truculência ontológica, como quando Bolsonaro reduz comunidades quilombolas a indivíduos mensurados por arrobas, como cabeças de gado. A truculência ontológica tem, no entanto, fundamento na ontologia econômica neoliberal, segundo a qual o universo socioeconômico é constituído por empresas e por indivíduos proprietários e nada mais (DEBREU, 1959). Thatcher estava ancorada em um prêmio Nobel da suposta ciência econômica (que, ao contrário das outras ciências, se autovalida com modelos matemáticos sem correspondência com fenômenos experimentais, o que equivale à definição da má metafísica por Kant).

Antropólogas e antropólogos são convocados hoje a responder perante juízes sobre a existência de entes coletivos, respostas que têm efeitos sobre seu destino. Para responder a essas demandas, nem o relativismo cultural nas duas formas mencionadas acima, nem o realismo científico são idôneos, e, tampouco, a convocação por Gaia, porque Gaia não é consenso científico aceitável por todos os juízes de boa-fé. Tomemos a situação em que está em julgamento a existência de comunidades tradicionais. Há coletividades que afirmam serem indígenas (Huni-kuin, por exemplo), quilombolas, ribeirinhos, caiçaras. Essas afirmações são apoiadas em narrativas dos mais velhos, em memórias, em objetos conservados, em sonhos, em rituais remanescentes. Por outro lado, seus vizinhos os discriminam negando que sejam "índios", movidos pelo interesse em desqualificá-los como sujeitos de direitos constitucionais. Mas há documentos em arquivos paroquiais, há objetos em museus associados, há evidências arqueológicas e imagens de satélite que atestam a existência e a continuidade da existência de povos autoidentificados. Essas evidências pragmáticas da existência histórica, apoiadas em critérios científicos, impõem-se aos que admitem a racionalidade e a diferença entre verdade e falsidade.

Tem lugar então uma luta pelo reconhecimento na esfera pública, ao longo da qual reconstituem-se coletivos locais e formam-se alianças com agentes externos - defensores 
públicos e procuradores da República, antropólogos e historiadores, arqueólogos e geocientistas, e também com federações, partidos - contra a coalizão de grileiros e do agronegócio que contestam a existência de comunidades indígenas e tradicionais, visando, assim, a expulsá-las de territórios a elas asseguradas pela constituição federal.

A luta pelo reconhecimento é a luta pela existência. A antropologia como disciplina digna do nome de ciência deve reconhecer autoconstituição de povos, e, ao mesmo tempo, a evidência científica - histórica, arqueológica e paleontológica - que confirma pragmaticamente essa existência no tempo e no território. A luta pela existência de povos é a luta ontológica como luta pelo reconhecimento da existência de povos indígenas, e o reconhecimento pragmático dessa existência nas comunidades científicas e jurídicas, bem como no espaço público. Para isso, porém, é preciso que a antropologia cultural e da ciência enfrente o desafio de conciliar o relativismo com o apoio à ciência.

\section{O Fim das Guerras da Ciência?}

Bruno Latour ofereceu em Paris uma entrevista à revista Science, em 2017, cuja apresentação sugeriu que o renomado historiador e etnógrafo da ciência teria de sua crítica à ciência como produtora de imagens da realidade ${ }^{4}$. A descrição dessa suposta reviravolta da visão de Latour face à ciência, na publicação oficial da Sociedade Americana para o Progresso da Ciência, deu a impressão de que as "guerras das ciências" teriam acabado com concessão de derrota por parte de Latour - assim como a Guerra Fria teria sido vencida pelos EUA com a queda do muro de Berlim. Mas a entrevista, ainda que "editada para maior clareza", permite entender que Latour se manteve fiel à crítica da visão das ciências como portadores da verdade e da racionalidade, embora afirmando a necessidade de aliança de humanistas, cientistas e do "jornalismo científico decente com revisão dos pares" ${ }^{\prime \prime}$. Isso se explica porque para Latour, a aliança entre humanistas (terranos) e cientistas não é ontológica ou epistemológica, e sim uma ação justificada pela situação de guerra.

Estamos de fato em guerra. Essa guerra é travada por uma mistura de megacorporações e alguns cientistas que negam a mudança climática - que têm fortes interesses na questão e que exercem uma grande influência na população. (LATOUR, 2017, p. 59)

\footnotetext{
4 "O sociólogo francês Bruno Latour, 70, há muito incomoda a ciência. Mas na época dos "fatos alternativos", sai em defesa dela. Aposentado no mês passado de suas obrigações oficiais na Sciences Po [a faculdade de Ciências Políticas de Paris], Latour celebrizou-se com o livro de 1979 intitulado Laboratory Life: The Construction of Scientific Facts, escrito em colaboração com o sociólogo britânico Steve Woolgar. [...] Uma noção central na obra de Latour é que fatos são construídos por comunidades de cientistas, e que não há distinção entre os componentes sociais e técnicos das ciências. Latour foi elogiado por sua abordagem e por suas ideias inovadoras, mas suas concepções relativistas e seu construtivismo social desencadearam reações. [...] O acirrado debate que se seguiu, conhecido como "guerras das ciências", durou vários anos. Em publicações posteriores, Latour admitiu que a [sua] crítica da ciência forneceu uma base para um pensamento anticientífico e, em particular, pavimentou o caminho para a negação da mudança climática - atualmente seu tema principal. Hoje, ele espera reconstruir a confiança na ciência" (Science, v. 358, n. 6.360, 2017). Sobre a "guerra das ciências", ver Almeida (1999).

5 Deborah Danowski e Eduardo Viveiros de Castro (2014). Sobre o Antropoceno, ver Bonneuil e Fressoz (2013); sobre a crise climática mundial, Marques (2015); sobre a aliança entre terranos e não humanos Schmitz (1965).
} 
Trata-se então de uma aliança justificada pela existência de um inimigo comum - como na aliança de comunistas e cristãos na resistência contra a ocupação alemã na França. Sob essa justificativa, Latour coloca como sua missão de apoiar a ciência como a tarefa de "apresentar a ciência como ciência em ação", deixando de lado a definição de ciência como atividade dirigida à busca de conhecimento ${ }^{6}$. Mas a "ciência em ação" é a ciência da incerteza, conforme diz Latour justificadamente - pois ciência lida com hipóteses e suas múltiplas consequências. Face ao uso que "negacionistas climáticos" fazem da incerteza de afirmações científicas, cientistas e filósofos da ciência distinguem a incerteza genérica sobre a realidade da incerteza de hipóteses que são postas à prova em experimentos - que testam sua verdade no sentido pragmático. Mas Latour não recorre a esse critério, e responde ao negacionismo climático com o seguinte programa de pesquisa:

Observarei geoquímicos, bioquímicos e geopolíticos, e conversarei com pesquisadores diferentes, usando uma abordagem lovelockiana, pressupondo que a Terra funciona como um sistema autorregulador. (LATOUR, 2017, p. 159, grifos meus)

Em livro publicado em português, em 2020, Latour afirma que há uma "denegação" da crise ecológica e sanitária pelo governo o de Bolsonaro, ou seja, a "[...] fuga das condições impostas pela terra [...]" (LATOUR, 2020, p. 10). A recusa do conhecimento científico é equiparada por Latour ao "[...] desvio da religião cristão, que se tornou uma fuga do mundo [...]" (LATOUR, 2020, p. 10). Trata-se de recusa do Antropoceno que afeta Gaia:

[...] simplesmente a consequência das sucessivas invenções dos viventes que acabaram transformando completamente as condições físico-químicas da terra geológica inicial [...]. Gaia são todos os seres vivos e as transformações materiais que eles submeteram à geologia, desviando a energia do sol para benefício próprio. (LATOUR, 2020, p. 11)

Latour combinou nessa afirmação uma visão pragmática de Gaia (efeitos das transformações físico-químicas da Terra), uma a visão agentiva de Gaia ("todos os seres vivos e as transformações materiais que eles submeteram à geologia"), e a visão termodinâmica da ciência ("desviando a energia do sol para benefício próprio") (LATOUR, 2017; 2020). Essa visão de Gaia - geoquímica, agencial, termodinâmica e religiosa parece ser destinada a obter a adesão de múltiplos povos. Mas resta dúvida sobre seu efeito de convencimento como ontologia multitética compartilhada por cientistas e pelos povos do planeta.

Por isso, permanece a pergunta: há um fundamento cognitivo e ético que justifique a coalização entre cientistas, humanistas e indígenas sobre mudança climática, pandemias globais, diversidade biológica, multiplicidade cultural e desigualdade social, e que, ao mesmo tempo, admita diferentes ontologias, como a de cientistas (realismo científico) e as de xamãs ameríndios? É o que vamos explorar a seguir, em busca de horizontes para uma ciência antropológica que admita a variedade infinita de mundos vividos e a possibilidade de tradução de critérios de verdade e da ética por meio de todos eles.

6 "We will have to regain some of the authority of science anew, scientists have to win back respect. But the solution is the same: You need to present science as science in action" (LATOUR, 2017). 


\title{
4 Ontologias Locais-Universais
}

\begin{abstract}
Descendo desses habitantes da terra das nascentes dos rios, filhos e genros de Omama. São as palavras dele, e as dos xapiri, surgidas no tempo do sonho, que desejo oferecer aqui aos brancos. Nossos antepassados possuíam desde o primeiro tempo. Depois, quando chegou a minha vez de me tornar xamã, a imagem de Omama as colocou em meu peito. Desde então, meu pensamento vai de uma para outra, em todas as direções; elas aumentam em mim sem fim. (KOPENAWA; ALBERT, 2015, p. 65)
\end{abstract}

Kopenawa é um sábio capaz de acessar mundos inacessíveis à experiência cotidiana. Essa descrição aplica-se também a físicos teóricos que elaboram ontologias cujas consequências pragmáticas são vividas em laboratórios por experimentalistas. A posição desses últimos cientistas pode ser comparada à de Kopenawa: são corpos preparados (pela educação, pelo treino experimental) para receber evidência de mundos que estão além da experiência cotidiana. Com a ressalva de que Kopenawa é também o cientista teórico que elabora uma cosmologia compatível com a evidência experimental.

\subsection{Malária e Água}

(1) Agentes de saúde dizem que malária [síndrome similar à da hepatite] é causada por mosquitos reproduzidos na água.

(2) Indígenas dizem que malária [identificada à síndrome de hepatite] é causada pela água - contaminada com oaca [vegetal cultivado que entorpece peixes] introduzido na água a montante por indígenas ("caboclos").

Como distinguir a explicação social da doença (como acusação contra indígenas que usam "oaca" nas cabeceiras) da explicação causal (consumo da água contaminada) e da explicação causal (mosquitos transmissores reproduzidos na água)? Na ausência de laboratórios locais, essa distinção é impossível.

\subsection{Pedras e Vida}

Adão Cardoso, zoólogo da Universidade Estadual de Campinas, foi incansável pesquisador e amigo de indígenas e seringueiros na Reserva Extrativista do Alto Juruá, juntamente com o professor Keith Brown Jr. A investigação de anfíbios em colaboração com Moisés Barbosa de Souza, da Universidade Federal do Acre, resultou em um inventário de 120 espécies de anfíbios (sapos e rãs) na bacia do Rio Tejo, território de 300.000 hectares no interior do que é hoje a Reserva Extrativista do Alto Juruá, evidenciando a conservação de altíssima biodiversidade onde indígenas e seringueiros vivem desde séculos (SOUZA, 2005). Em 1995, Adão participou de um curso para os seringueiros e indígenas no rio Juruá, encarregando-se do ensino da biologia. Na primeira aula, Adão introduziu a diferença entre vida e não vida, com a pergunta: "Pedras não têm vida, certo?". Em vez da resposta esperada, "sim", recebeu uma enxurrada de contestações que ocuparam toda a aula, se prolongaram durante as conversas noturnas e comprometeram 
a continuidade do curso. Osmildo, índio Kuntanawa e seringueiro, argumentou: "Pedra cresce". Osmildo se referia ao fato de que na bacia do rio Juruá pedra existe no leito do rio Juruá-Mirim, mina (brota) do leito do rio, assim como a água mina da terra.

A noção de que pedra mina da terra, assim como a água mina de fontes, corresponde à noção andina segundo a qual ouro e prata crescem no seio da mãe-terra. Analogamente, no rio Juruá, pedras cresceriam no fundo do rio Juruá-Mirim. Adão argumentou: "Se você separar um pedaço de pedra do fundo do rio e colocá-lo na mesa, esse pedaço não cresce, certo?" Osmildo retrucou: "Se você cortar o braço de uma pessoa e colocá-lo na mesa, ele morre". Esse não foi o último argumento dos indígenas e seringueiros em conversas continuadas ao longo da noite. No leito do rio Juruá, nos barrancos e nas corredeiras, abundam ossos fossilizados de animais que são versões ampliadas de animais contemporâneos: ossos de tatus, tamanduás, tartarugas, preguiças, ampliados desmesuradamente e com forma de pedra. Esse fato é apresentado pelos moradores como evidência de que ossos se convertem em pedra e crescem em tamanho quando submersos na água.

\subsection{Formiga Vira Planta}

Em nossa experiência de pesquisa colaborativa junto a seringueiros e indígenas no alto rio Juruá, apareceu frequentemente a seguinte afirmação: formiga vira cipó. Essa afirmação nunca foi abalada por fotografias de biólogos de nossa equipe que mostravam brotos de planta saindo de olhos de formigas. Ao contrário, essas imagens eram usadas como evidência de que de fato "formiga vira cipó". Essa afirmação fenomenológica é encontrada em relatos de Piro no Ucayali, de Maués do Solimões, nos seringueiros e Caxinauá do Juruá, e entre ribeirinhos do vale do Xingu. Trata-se de fenômeno identificado em toda a bacia amazônica por diferentes povos. Há uma ampla literatura sobre a afirmação de povos amazônicos segundo a qual "inseto viram planta". Em conversa com um morador do rio Juruá por volta de 2010, aprendi uma versão mais elaborada da teoria, na forma de variantes de "inseto vira cipó".

Quadro 1 - Inseto vira cipó

\begin{tabular}{|l|l|l|l|}
\hline \multicolumn{1}{|c|}{ Inseto } & \multicolumn{1}{c|}{ Cipó } & Moradia do inseto & \multicolumn{1}{c|}{ Hábito } \\
\hline Formiga Tucandeira & Cipó-titica & No alto & De cima para baixo \\
\hline Gafanhoto & Cipó-ambé & No alto & De cima para baixo \\
\hline Grilo-da-perna-dura & Timbó & No alto & De cima para baixo \\
\hline Cigarra, mariposa & Tracuá & No alto & De cima para baixo \\
\hline Caranguejeira & Japecanga & Debaixo da terra & De baixo para cima \\
\hline
\end{tabular}

Fonte: Relato de Agricultor de Marechal Thaumaturgo em 2012 
O quadro seguinte vem de uma publicação científica:

Quadro 2 - Inseto, fungo, cipó

\begin{tabular}{|c|c|c|}
\hline "Inseto" & Cipó - bejuco & Nome do vegetal \\
\hline $\begin{array}{l}\text { formiga conga } \\
\text { tucandeira }\end{array}$ & $\begin{array}{l}\text { bejuco yaré } \\
\text { cipó titica }\end{array}$ & Heteropsis flexuosa \\
\hline $\begin{array}{l}\text { Alacrán/ } \\
\text { escorpião }\end{array}$ & $\begin{array}{l}\text { bejuco gio ou bejuco de mareo } \\
\text { (Araceae) }\end{array}$ & Araceae \\
\hline mariposa Janabuyagi & bejuco Nodokio ou falso burro & Araceae, \\
\hline Jebaiycuma & bejuco Narao ou bejuco de flema & Philodendron hylaeae, Araceae \\
\hline aranha & mata palo, Viripiti & $\begin{array}{l}\text { Oryctanthus alveolatus, } \\
\text { Loranthaceae }\end{array}$ \\
\hline
\end{tabular}

A formiga conga (Paraponera clavata) é a formiga tucandeira; o bejuco de yaré é o cipó-titica (Heteropsis flexuosa (Aracea). O fungo Cordyceps é o parasita associado às "formigas-zumbi".

Fonte: Vasco-Palacios et al. (2008)

A conclusão dos autores do estudo é que "[...] a perda do conhecimento das etnias indígenas leva à desaparição de um acúmulo de informações muito valiosas sobre a biologia e a ecologia de plantas, animais e fungos [...]" (VASCO-PALACIOS et al., 2008, p. 27), e que a colaboração pode contribuir ao conhecimento científico ao fornecer informações sobre aspectos pouco conhecidos da floresta tropical úmida, assim como sobre as interações ecológicas entre organismos, neste caso, entre fungos-plantas e fungosanimais, servindo de ponto de partida para a realização de investigações científicas que corroborem e aprofundem o conhecimento dessas relações (VASCO-PALACIOS et al., 2008). Vasco-Palacios et al. (2008, p. 17) dizem que associações entre insetos e plantas são uma pequena parte dos "[...] conhecimentos sobre os fungos e as suas relações ecológicas com animais e plantas [...]" dos indígenas. E que refletem, além disso, "[...] a capacidade integradora e descritiva que os indígenas possuem sobre o meio natural que os circunda $[\ldots]^{\prime \prime}$, incluindo

[...] dados de besouros (Coleoptera) e larvas (Diptera), mamíferos, veados (Mazama americana e M. gouazoubira) e esquilos (Microsciurus flaviventer), e tartarugas que incluem fungos nas suas dietas, assim como sobre espécies de fungos que parasitam plantas e insetos. (VASCO-PALACIOS et al., 2008, p. 17, grifos meus)

O depoimento do morador de Thaumaturgo e de muitos outros testemunhos mostram que há uma ciência fenomenológica generalizada de indígenas e caboclos que acessa fenômenos biológicos de grande relevância, exemplificados pelas interações entre insetos e vegetais.

\section{Mundos Ressurgentes}

O programa de pesquisa de Anna Tsing é exemplo paradigmático de uma alternativa de busca do conhecimento que envolve coletivos de cientistas, antropólogas, habitantes, fungos e instrumentos, sem fronteiras entre o que é natural e artificial, pesquisadores 
e nativos, local e global, ou humano e não-humano. Essa antropologia generalizada inclui entes vegetais e humanos deslocados na escala mundial em consequência do tráfico biológico e de migrações pós-coloniais. Tsing trata de entes coproduzidos pela destruição da natureza no noroeste dos EUA e do ressurgimento de paisagens com fungos transcontinentais, de migrantes asiáticos e mercados modernos norte-americanos. Ressurgência é o conceito-chave de Tsing: contraposição à entropia cultural como o ressurgência. Contraentropia: reorganização de paisagens e povos nos escombros ecológicos e sociais produzidos pelo capitalismo. O fenômeno da ressurgência - a proliferação de novos entes sociais e biológicos a partir dos escombros das guerras coloniais e da destruição capitalista de paisagens de Oregon - é a uma importante correção à visão entrópica da história formulada por Lévi-Strauss e pelo anjo da história que segundo Benjamin só vê atrás de si a destruição (ALMEIDA, 1990). Na versão de Tsing, nos escombros produzidos pelo capitalismo emergem espécies, comunidades e metafísicas imprevisíveis.

\section{Muitos Mundos}

A oposição entre "muitos mundos" de cosmologias locais e um único mundo do realismo científico pode ser representada assim:

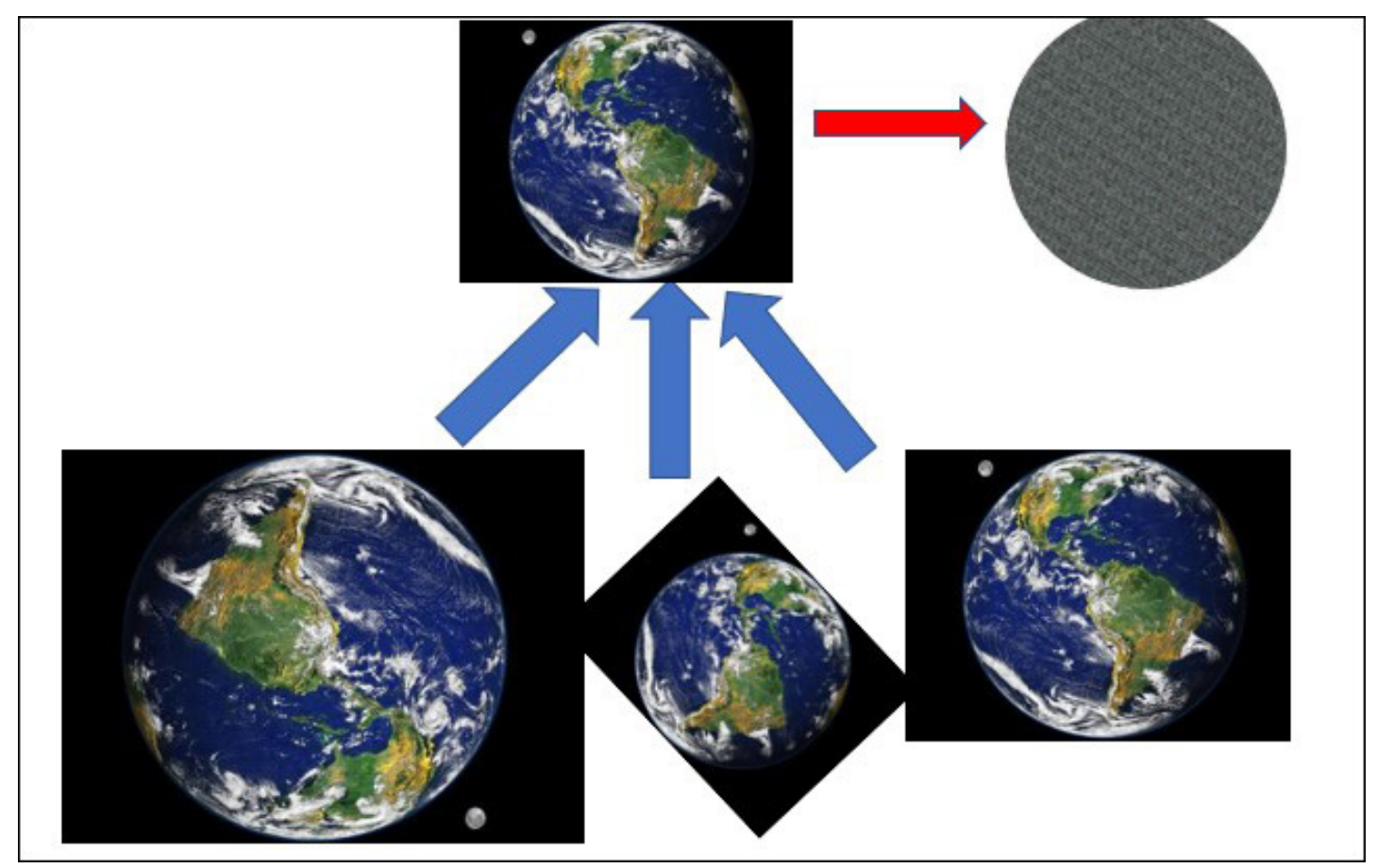

Figura 1 - Múltiplos mundos e degradação

Fonte: Elaborada pelo autor deste artigo (com imagens da Terra capturadas no Google Earth)

A Figura 1 ilustra o fato de que diferentes ontologias sobre o mundo (parte inferior do quadro) convergem ao prever a degradação que leva a um fim do mundo - mundo em que a entropia é máxima.

Sobre o lugar de Oregon na cultura norte-americana, ver Ursula le Guin: O Látego dos Céus (The Lathe of Heaven, literalmente o Torno dos Céus). 
E há uma maneira de expressar esse ponto de maneira ainda mais clara. Seringueiros do rio Tejo criaram a primeira Reserva Extrativista do país, ou seja, unidade de conservação destinada ao uso sustentável de comunidades tradicionais locais. Francisco Barbosa de Melo, líder local que levou a esse resultado, sem nenhuma educação formal, elaborou um mapa da região usando recursos de um computador. Na imagem a seguir, mostramos um mapa georreferenciado da Reserva Extrativista, e o mapa de Chico Ginu. Os dois mapas parecem à primeira vista discordantes, mas quando a orientação alto-baixo é invertida, o mapa de Chico Ginu mostra-se compatível com o mapa georreferenciado de Alan Monteiro. Essa discordância não é apenas a mudança de referencial do "norte" para o "sul" (onde nos mapas locais o "norte" está "no baixo", sendo a direção para onde fluem os rios). Há mais que isso, porque sob essa visão todos os rios fluem de um único "alto" para o "baixo" - ponto terminal que é visto com um lago, ou como o mar (POSTIGO, 2010). Na imagem a seguir, o triângulo representa uma visão da terra como cone, de cujo topo correm rios para a margem que é o oceano. Essa representação foi formulada por um seringueiro ao visitar São Paulo, e assim comprovando que o rio Amazonas não levava a essa cidade - e que, portanto, haveria diversos rios saindo do "alto" para o "baixo". Sua hipótese foi a imagem de uma terra cônica - com vários rios levando de um único alto para "baixos" espalhados na base.

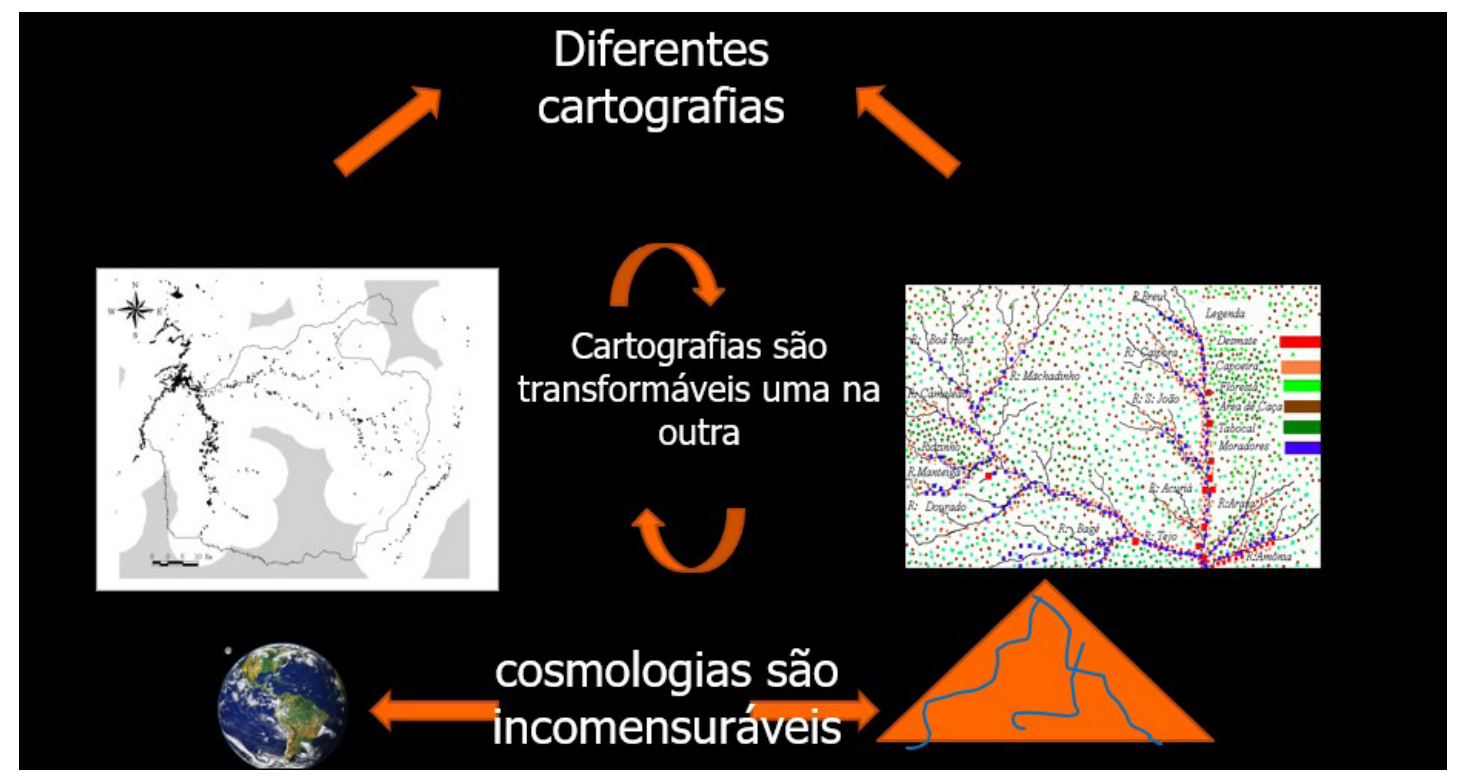

Figura 2 - Ontologias incomensuráveis são compatíveis pragmaticamente

Fonte: Elaborada pelo autor deste artigo e Almeida et al. (2016)

O trabalho de Augusto Postigo e de Antônio Barbosa de Melo mostra que ontologias se transformam em contato com a experiência - assim como teorias científicas. 
Figura 3 - Ontologias de sustentabilidade

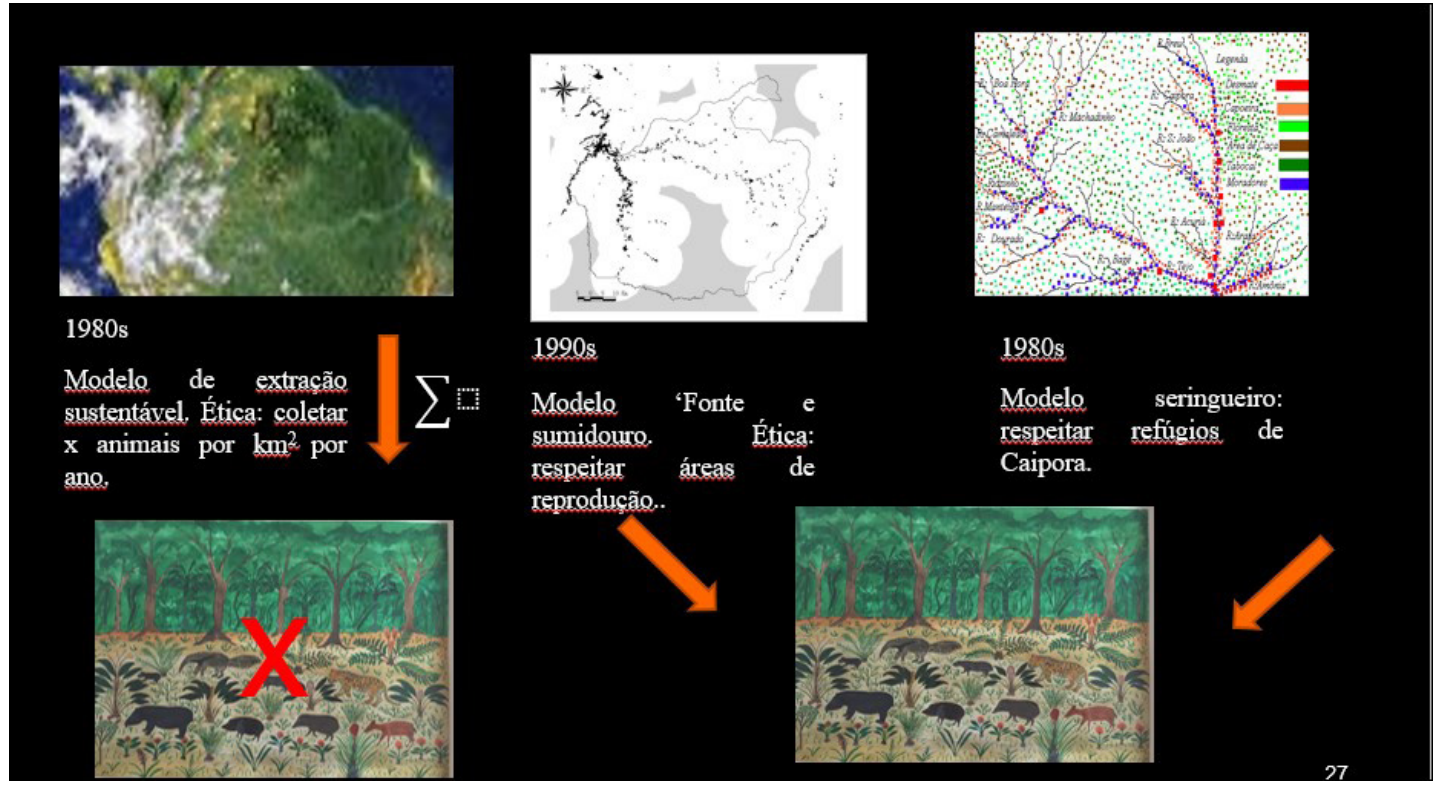

Fonte: Elaborada pelo autor deste artigo, Almeida et al. (2016) e Carneiro da Cunha e Almeida (2002)

Na década de 1980, havia um modelo de "extração sustentável" que preconizava para cada espécie de animal (e.g. veados, pacas, queixada, porquinho) uma quantidade que poderia ser predada "otimamente" sem prejuízo para a continuidade da população. Esse modelo não levou a predições pragmáticas face a dados de pesquisa na Reserva Extrativista do Alto Juruá (lado esquerdo do diagrama). Por outro lado, um modelo chamado de "fonte e sumidouro" (source and sink) mostrou-se compatível com os dados empíricos obtidos pelos seringueiros-pesquisadores. Esse modelo tomava como variável a proporção do território excluída da atividade de caçadores. E essa tese correspondia com a tese dos moradores, segundo a qual a continuidade da população da fauna cinegética dependia da existência de refúgios - na qual Caipora protege e cura animais visados pela caça.

\section{Desafio da Antropologia Atual}

Como articular antropologicamente o consenso científico sobre aquecimento, pandemias e agroindústria na escala global, respeitando a incomensurabilidade de ontologias locais? Esse é o teste que contrasta o relativismo cultural de múltiplos mundos com a nova aliança com cientistas cujo realismo científico afirma a existência de um mundo real onde existem fungos, vírus e aquecimento global. A pergunta remete ao fato de que diferentes culturas veem fenômenos como o coronavírus sob diferentes quadros ontológicos ${ }^{8}$. Respondo a essa pergunta com a suposição de que é possível preservar a distinção entre verdade e falsidade (fake news), e entre falácia (irracionalidade) e racionalidade, mantendo, ao mesmo tempo, o pressuposto de que há múltiplos mundos?

\footnotetext{
8 Camargo (2020) e Lagrou (2020) tratam de visões indígenas do povo Caxinauá sobre a pandemia do "novo coronavírus".

9 Sobre duas formas de relativismo, o relativismo cultural e o relativismo estrutural, ver Almeida (2003).
} 
A agenda das humanidades não é a guerra contra a ciência. Em vez disso, deve dar conta da distinção entre pseudoverdades (mentiras e fake news) e pseudoargumentos (falácias), preservando, ao mesmo tempo, a validade de múltiplas ontologias e de diferentes lógicas. Verdade pragmática é o chão comum de múltiplas ontologias e o critério que permite distinguir entre elas falácias e mentiras de raciocínios consistentes e verdades de fato. Verdade no sentido pragmático significa que a afirmação de um fato é acompanhada pela descrição das condições em que esse fato pode ser verificado em um experimento. Verdades pragmáticas são compatíveis com diferentes ontologias. Mas permanece a exigência de verificação pragmática dessas ontologias.

Há uma ontologia em que existem espíritos desencarnados, e um mundo em que esses entes não existem. Os relatos etnográficos de uma antropóloga espírita, Maria, serão os mesmos que os de outra aluna agnóstica - se seguirem os protocolos da etnografia, que incluem registros em diários de campo, gravador, fotografias, documentos, censos, mapas e orçamentos domésticos. Esses protocolos deveriam ser os mesmos para Maria e para João, antropólogo materialista. Esses registros pragmáticos podem ser compatíveis, corroborando a ontologia em que há espíritos e a ontologia agnóstica em que não existem espíritos. Não preciso impor à minha aluna uma dessas ontologias para reconhecer a veracidade da etnografia produzida por ela.

Moral da história: critérios pragmáticos de verdade são compatíveis com múltiplas ontologias. O interesse para a antropóloga é que a noção de quase-verdade (ou verdade parcial, ou verdade pragmática) dá consistência a historicidade à localidade do predicado-verdade, permitindo sua compatibilidade com a multiplicidade de ontologias. A concordância pragmática é a concordância sobre verdades locais - porque são compatíveis com múltiplas ontologias. No exemplo anterior, significa minha concordância com a antropóloga espírita, porque ela segue os protocolos da pesquisa científica, embora interprete os resultados segundo uma ontologia diferente da minha.

Enfatizo esse ponto para dizer que a noção de "concordância pragmática" nada tem a ver com "acordos para fins práticos" - um faz de conta em que fingimos concordância para obter vantagens. Trata-se do reconhecimento de que existem critérios pragmáticos de verdade que são válidos em diferentes visões de mundo: o reconhecimento da diferença entre vida e morte, entre dor e prazer. Como Frege observou, a estrela-d'alva e a estrela vésper se referem ao mesmo planeta, mas têm sentidos diferentes; o sete-estrelo de camponeses e as plêiades da mitologia européia, assim como o subaru da tradição japonesa (com seis estrelas), se referem à mesma constelação dos astrônomos, embora sejam entes ontologicamente diferentes. Há cientistas espíritas, umbandistas e taoístas, cristãos e ateus, que concordam sobre a existência da estrela denominada diferentemente. Newton Freire-Maia, geneticista de populações, é exemplo de cristão cuja visão de compatibilidade entre sua ontologia e a prática científica está documentada em livro póstumo com prefácio de Newton Da Costa (FREIRE-MAIA, 2008).

Mas assim como pode haver concordância pragmática entre ontologias diversas, ocorrem também conflitos ontológicos cuja extensão é a guerra de aniquilação, como quando colonizadores têm o intuito de exterminar o mundo dos xamãs matando os portadores das metafísicas locais, destruindo os locais de culto e os objetos e substâncias sagradas que servem de mediação entre o mundo cotidiano e o mundo invisível de 
espíritos. Uma variante dessas guerras de aniquilação ontológica é um sistema escolar que reprime visões de mundo e sabedorias locais. Nos dois casos, trata-se de invasões ontológicas de cunho missionário (com a implantação de igrejas locais como cabeças de ponte da cosmologia evangélica) ou de invasões pseudocientíficas em que dogmas escolares são inculcados sem apoio na sabedoria preexistente dos povos indígenas e das comunidades camponesas.

\section{Realismo e Mutirealismo}

Formulamos acima um dilema: ou há um único mundo do realismo científico ocidental moderno ou há vários mundos correspondentes a cada cultura e a cada povo. Há uma resposta a esse dilema que consiste em afirmar que vivemos em um mundo único composto de vários mundos locais - e conforme essa tese, o mundo do realismo científico é pressuposto, mas acomoda uma variedade de pseudomundos locais, que são representações admitidas caridosamente como versões aproximadas do mundo real único. Mas não queremos essa atitude, na qual o realismo científico adota a posição tolerante de uma ontologia filtrante que recupera de visões locais traços que a corroboram.

Não queremos essa atitude porque ela equivale a legitimar a ocupação ontológica da ciência e da teologia ocidental na escala da ocupação colonial - ou em outros termos, equivale à efetivação do colonialismo ontológico em pele de cordeiro. Não há tradução ontológica inocente, porque é impossível traduzir ontologias a não ser como substituição ontológica - cabeça de ponte em guerras ontológicas. E a alternativa a isso já foi indicada, a saber em vez de imposição de ontologias, ressaltar a convergência pragmática e racional de múltiplas visões de mundo.

\section{A Virada Pragmática da Antropologia}

A posição defendida acima significa a exigência de uma virada pragmática na antropologia. Essa virada pragmática significa reconhecer o contato entre ontologias e encontros pragmáticos que transpõem fronteiras ontológicas. Por exemplo, o aquecimento global, conforme a ontologia da ciência climática, é apoiado por inúmeros sensores dispostos ao redor do planeta, cujos dados são agregados em modelos matemáticos que geram indicadores médios estendidos à escala global. Quando descemos à escala local, a comunidade Ashaninca aponta o fenômeno de animais-mestres que perdem a capacidade de indicar fidedignamente mudanças sazonais - como se fossem sensores sujeitos eles mesmos à entropia que afeta o ambiente que deveriam monitorar. Os Ashaninca mais velhos evocavam como explicação para a mudança o retorno do Inca-Sol à terra, tendo como consequência o aquecimento (MESQUITA, 2012; 2013).

Na mesma região do alto Juruá acreano, descendente de migrantes nordestinos interpretavam as mudanças ambientais percebidas nos quadros das visões apocalípticas difundidas em folhetos populares das décadas de 1960 e de 1970, nos quais previsões climáticas anunciaram o aumento progressivo do calor e da intensidade de secas, ao mesmo tempo que relacionavam essa progressão à crise moral e sexual como indicadores 
da iminência do fim do mundo. Um poeta nordestino explicou esse "fim do mundo" como o tempo em que "a roda grande passará dentro da roda menor" - a realização de uma impossibilidade lógico-empírica, como culminação de uma crise crescente do mundo natural e do mundo social, que era claramente a metáfora para uma transformação social e cósmica (ALMEIDA, 1979). Finalmente: em um seminário na Universidade Federal de Pernambuco, uma contribuição estudantil tratou da "construção social da seca" no sertão paraibano como efeito progressivo de políticas que estimulam substituição da paisagem da catinga por paisagens irrigadas para produção comercial, em combinação com efeitos do El Niño. Tudo se passa como se a visão Ashaninca, o milenarismo camponês e teorias climáticas convergissem em suas consequências observáveis, embora inteiramente divergentes às suas ontologias implicadas.

Nos exemplos acima, a verdade local (i.e. dados de hidrômetros, de camponeses/ indígenas leitores de sensores de pássaros, de plantas, da umidade e do aspecto da lua) é estendida de diferentes modos a uma verdade universal. Em uma direção, dados climáticos são estendidos de modo a se tornarem compatível com uma metafísica onde o Cacique Cobra Coral manipula o clima com apoio de cientistas (TADDEI, 2017); em outra, fenômenos de seca são explicados nos termos da narrativa apocalíptica; e em outra, pelos efeitos da atividade agronegocista. Há cientistas espíritas, umbandistas e taoístas, sem falar dos cristãos ${ }^{10}$. Essas orientações pressupõem ontologias distintas, e todas elas incompatíveis com a ontologia minimalista e unitária do realismo científico.

Entre elas, as cosmologias indígenas têm lugar. Lévi-Strauss reabilitou os mitos indígenas sul-americanos, tratados como pensamento coletivo que reflete sobre problemas cosmológicos e humanos. Eduardo Viveiros de Castro destacou a contribuição filosófica aí implicada, ressaltando que havia nesse pensamento uma alternativa ao cogito cartesiano que afirmou "Penso, logo existo". A alternativa ameríndia seria: "Penso em outro, logo existe um outro que pensa sobre mim". De onde a existência subjetiva-objetiva remete a uma relação com um sujeito-objeto que é equivalente a mim mesmo como sujeito pensante. Essa explosão do ponto de partida ontológico ego-centrado foi formulada por Viveiros de Castro como posição antinarcisística, e corresponde à atitude de Montaigne e de Rousseau sobre a natureza humana como multiplicidade aberta à incerteza da existência.

\section{Conclusões}

Verdade pragmática é o chão comum de múltiplas ontologias. Verdade pragmática é compatível com a incomensurabilidade de ontologias. Há um mundo em que existem espíritos desencarnados, e mundo em que esses entes não existem. Minha aluna pertence ao primeiro mundo, e eu pertenço ao segundo. Ela e eu admitidos os mesmos dados etnográficos obtidos por meio de instrumentos do ofício - diário de campo, gravador, máquina fotográfica -, e os resultados incluem censos, mapas e orçamentos domésticos. Esses registros são verdadeiros no sentido pragmático: trata-se de resultados e de registros

${ }_{10}$ Newton Freire-Maia, um importante geneticista de populações, é exemplo de cristão cuja visão de compatibilidade entre sua ontologia e a prática científica está documentada em livro póstumo com prefácio de Newton Da Costa. 
de aparelhos e de observações. Concordância pragmática é a concordância sobre verdades locais de fato - compatível com discordância ontológica. Não é o "faz-de-conta" em que o colonizador finge que aceita crenças locais para dominar os nativos.

Realismos e mutirrealismos: formulamos acima um dilema antropológico, ou há um único mundo do realismo científico ocidental moderno ou há vários mundos correspondentes a cada cultura e a cada povo. Uma primeira resposta: há um mundo (global) composto de vários mundos (locais). Essa tese permite tomar o mundo do realismo científico como o mundo global, e a composição de mundos como o conjunto de mundos locais filtrados pela compatibilidade com o mundo global. Mas não queremos impor esse filtro aos conhecimentos e mundos locais, onde a ontologia global é a ontologia filtrante que recupera de cada ontologia local os traços que a corroboram ${ }^{11}$. Não queremos essa atitude porque ela equivale à ocupação ontológica da ciência ocidental na escala terrestre - ou em outros termos, à efetivação do colonialismo ontológico, como na filtragem de cosmologias locais em invasões missionárias pela tradução da Bíblia em idiomas nativos, e pela ocupação científica com manuais em que conhecimentos indígenas são filtrados pela divulgação científica. Toda tradução de ontologias é uma ocupação ontológica em pele de cordeiro. Não há tradução ontológica inocente, porque é impossível traduzir ontologias a não ser como substituição ontológica - cabeça de ponte em guerras ontológicas.

A alternativa a isso foi indicada acima: conviver com a incomensurabilidade ontológica, admitindo a concordância pragmática sobre as consequências de distintas ontologias.

A atitude antropológica recomendada pela "virada ontológica" é a suspensão de ontologias (conscientes ou inconscientes) do antropólogo. A tarefa seguinte é a reconstrução das ontologias locais que dão conta dos fenômenos, E a dificuldade aqui - evidenciada por Roy Wagner como "equivocação" e qualificada por Viveiros de Castro como "equivocação controlada" (VIVEIROS DE CASTRO, 2015) está no fato de que, nessa reconstrução, imiscui-se inevitavelmente a interação de pressupostos ontológicos do pesquisador e as ontologias locais. Essa interação implica a modificação da ontologia da etnógrafa por efeito da experiência de campo, e a modificação das ontologias locais como efeito da atuação da etnógrafa. Não apenas isso: ao salvar objetos da cultura local da desaparição, esses objetos mudam de estatuto ontológico. Ou ainda, na formulação de Manuela Carneiro da Cunha, cultura e "cultura" não têm o mesmo estatuto ontológico e político. Temos que conviver com a multiplicidade ontológica: como zonas de conflito e de comunicação entre povos, como espaços de diferença no interior de uma mesma sociedade, e como multiplicidade subjetiva de multi-indivíduos.

Verdades locais e sua universalização: nos exemplos acima, a verdade local da experiência (i.e. dados de hidrômetros, de camponeses/indígenas leitores de sensores de pássaros, de plantas, da umidade e do aspecto da lua) são estendidas por cada comunidade de conhecimento a uma verdade global - quando acrescentamos a ela uma ontologia que em tudo corrobora as verdades locais. Em uma ontologia possível, o clima é afetado pelo Cacique Cobra Coral (TADDEI, 2017); na outra, é determinado pela narrativa do Apocalipse

\footnotetext{
${ }^{11}$ Deborah Lima apontou para mim que o título do livro editado em 2018 por Mario Blaser e Marisol de la Cadena, A World of Many Worlds, aponta para um mundo composto de vários mundos. Philippe Descola afirma que uma composição de mundos não implica um único mundo resultante dessa composição (DESCOLA, 2014).
} 
bíblico; em outra, por um modelo de aquecimento global causado pela atividade industrial humana. Há cientistas espíritas, umbandistas e taoístas, sem falar dos cristãos - Newton Freire-Maia, um importante geneticista de populações, é exemplo de cristão cuja visão de compatibilidade entre sua ontologia e a prática científica está documentada em livro póstumo com prefácio de Newton Da Costa. Essas orientações pressupõem ontologias distintas, e todas elas incompatíveis com a ontologia minimalista do realismo científico. Entre elas, as cosmologias indígenas têm pleno lugar. Lévi-Strauss reabilitou os mitos indígenas sul-americanos, tratados como pensamento coletivo orientado para refletir recursivamente sobre problemas cosmológicos e humanos. Eduardo Viveiros de Castro destacou a contribuição epistemológica implicada. Isto é, ele percebeu que há uma alternativa ao cogito egocêntrico: "Eu penso, logo eu existo". Essa alternativa, presente na filosofia ameríndia, seria: "Eu penso sobre um outro, logo há um outro que pensa sobre mim", de onde resulta que minha existência (ente pensante) depende de alguém que pense como eu (outro ente pensante). Essa explosão do ponto de partida ontológico ego-centrado foi formulada por Viveiros de Castro como posição antinarcisística, e corresponde à atitude de Montaigne e de Rousseau sobre a natureza humana como multiplicidade aberta à incerteza da existência em contraste com o postulado de um sujeito humano universal de Descartes a Kant ${ }^{12}$.

É possível conciliar a luta contra a destruição planetária da diversidade biológica e cultural com a autonomia ontológica de culturas. Ontologias do mundo inteiro podem unirse sob a bandeira da verdade pragmática e da racionalidade. Isso porque ontologias dizem respeito a visões de mundos que estão além da experiência, mas que são indispensáveis para guiar a ação para além dos dados da experiência anterior. Múltiplas ontologias associadas às ciências e às visões de mundo locais podem, portanto, se aliar contra a destruição de um mundo comum, que é o mundo acessível pragmaticamente por efeitos como a poluição de rios, a irregularidade dos ritmos naturais, pelo aquecimento inusitado, pelas inundações e secas extraordinárias - bem como pelos fenômenos sociais associados, tais como fomes, desemprego e mortalidade. Face a esses fenômenos, cabe à antropologia afirmar critérios de prudência e de justiça como "não deixar pessoas para trás", ou seja, sustentar direitos mínimos à vida e ao bem-estar para todo ente humano e similar a humanos.

\section{Referências}

ALMEIDA, Mauro W. B. Folhetos - A literatura de cordel no nordeste brasileiro. 1979. 400p. Dissertação (Mestrado) - Universidade de São Paulo, São Paulo, 1979.

ALMEIDA, Mauro W. B. Symmetry and Entropy: Mathematical Metaphors in the work of Lévi-Strauss. Current Anthropology, [s.l.], v. 31, n. 4, p. 367-385, 1990.

ALMEIDA, Mauro W. B. Guerras Culturais e Relativismo Cultural. Revista Brasileira de Ciências Sociais, [s.l.], v. 14, n. 41, p. 5-14, outubro, 1999.

\footnotetext{
12 Não podemos aqui tratar das origens da Antropologia a partir de Herder e de Wilhelm von Humboldt, que se distanciam de Kant precisamente sobre a recusa da distinção entre "antropologia pragmática" (variedade empírica de povos humanos) e "antropologia transcendental" unidade a priori de um sujeito humano universal excluindo a diversidade (e.g. de lógicas, de metafísicas, de moralidade)
} 
ALMEIDA, Mauro W. B. et al. In: SIVIERO, Amauri et al. (org.). Etnobotânica e

Etnobotânica Econômica do Acre. Rio Branco, AC: Editora da Universidade Federal do Acre, 2016. p. 14-37.

ALMEIDA, Mauro W. B. Relativismo Antropológico e Objetividade Etnográfica. Campos, [s.l.], v. 3, p. 9-29, 2003.

ALMEIDA, Mauro W. B. Relatividade, relativismo cultural e estruturalismo: influências de Einstein na Antropologia. In: KNOBEL, Marcelo; SCHULZ, Peter (org.). Einstein: muito além da relatividade. São Paulo: Instituto Sangari, 2010. p. 123-142.

ARENDT, Hanna. Entre o Passado e o Futuro. Tradução de Mauro W. B. Almeida. São Paulo: Perspectiva, 2014.

BONNEUIL, Christophe; FRESSOZ, Jean-Baptiste. L'événement anthropocêne: La Terre, l'histoire et nous. Paris: Éditions du Seuil, 2013.

BUENO, Octavio; DE SOUZA, Edelcio G. The Concept of Quasi-Truth. Logique \& Analyse, [s.l.], v. 153-154, p. 183-199, 1996.

CAMARGO, Eliane. A COVID-19 vista pelos caxinauás. Uma contribuição etnolinguística. [2020]. Disponível em: https://www.abralin.org/site/a-covid-19-vista-peloscaxinauas-uma-contribuicao-etnolinguistica-por-eliane-camargo/. Acesso em: 10 dez. 2020.

CARNEIRO DA CUNHA, M. M.; ALMEIDA, M. W. B. (org.). Enciclopedia da Floresta. São Paulo: Companhia das Letras, 2002.

DA COSTA, Newton. Lógica Indutiva e Probabilidade. 2. ed. São Paulo: Hucitec-EDUSP, 1993.

DA COSTA, Newton. O conhecimento Científico. São Paulo: Fapesp e Discurso Editorial, 1997.

DANOWSKI, Débora; VIVEIROS DE CASTRO, Eduardo. Há mundo por vir? Ensaio sobre os medos e os fins. Florianópolis: Desterro; Cultura e Barbárie; Instituto Socioambiental, 2014.

DEBREU, Gérad. Theory of Value: an Axiomatic analysis of Economic Equilibrium. New Haven e Londres: Yale University Press, 1959.

DESCOLA, Philippe. La Composition des Mondes - Entretiens avec Pierre

Charbonnier. Paris: Flammarion, 2014.

FREIRE-MAIA, Newton. Verdades da Ciência e Outras Verdades: a visão de um cientista. São Paulo: Editora Unesp; Sociedade Brasileira de Genética, 2008.

FRENCH, Stephen; DA COSTA, Newton. Science and Partial Truth: a Unitary Approach to Models and Scientific Reasoning. Oxford: Oxford University Press, 2003.

HEIDEGGER, Martin. Ser e Tempo. Tradução de Fausto Castilho. Campinas: Editora da Universidade Estadual de Campinas, 2012.

HUSSERL, Edmund. Investigações Lógicas. Trad. Pedro M. S. Alves e Carlos Aurélio Morujão. Lisboa: Centro de Filosofia da Universidade de Lisboa, 2007

KOPENAWA, Davi; ALBERT, Bruce. A Queda do Céu: palavras de um xamã yanomami. São Paulo: Companhia das Letras, 2015.

LAGROU, Els. Nisun: a vingança do povo morcego e o que ele pode nos ensinar sobre o novo coronavírus. [2020]. Disponível em: https://blogbvps.wordpress.com/2020/04/13/nisun-avinganca-do-povo-morcego-e-o-que-ele-pode-nos-ensinar-sobre-o-novo-corona-virus-por-elslagrou/. Acesso em: 10 dez. 2020.

LATOUR, Bruno. Entrevista - Bruno Latour, a veteran of the science wars, has a new mission. Science, [s.l.], v. 358, n. 6.360, 2017. 
LATOUR, Bruno. Diante de Gaia. São Paulo: UBU e Atelier de Humanidades, 2020.

MARQUES, Luiz. Capitalismo e Colapso Ambiental. Campinas: Editora Unicamp, 2015.

MESQUITA, Érika. Ver de Perto para Contar de Certo: as mudanças climáticas sob os olhares dos moradores da floresta do alto Juruá. 2012. 489 p. Tese (Doutorado) - Universidade Estadual de Campinas, São Paulo, 2012.

MESQUITA, Érika. Ex-rubber tappers and small farmers views on weather changes in the Amazon. In: UNESCO. World Social Science Report: Changing Global Environments. Paris: UNESCO, 2013. p. 277-279.

MIKENBERG, Irene; DA COSTA, Newton C. A.; CHUAQUI, Rolando. Pragmatic Truth and Approximation to Truth. Journal of Symbolic Logic, [s.l.], v. 51, n. 1, p. 201-221, 1986.

PEIRCE, Charles S. Collected Papers of Charles Sanders Peirce. Cambridge: Harvard University Press, 1932. (Volume II: Elements of Logic)

PEIRCE, Charles S. The Essential Peirce. Bloomington: the Indiana University Press, 1998. v. 2 (1893-1913).

PESSOA JR., Osvaldo. Conceitos de Física Quântica. 3. ed. São Paulo: Editora Livraria da Física, 2006. v. I.

POPPER, Karl. A Lógica da Pesquisa Científica. Tradução de Leônidas Hegenberg e Octanny Silveira da Mota. São Paulo: Cultrix e Editora da Universidade de São Paulo, 1975 [1935].

POstigO, Augusto A. A Terra Vista do Alto: usos e percepções acerca do espaço entre os moradores do Rio Bagé, Acre. 2010. 311 p. Tese (Doutorado) - Universidade Estadual de Campinas, 2010.

POVINELLI, Elizabeth. Radical Worlds: The Anthropology of Incommensurability and Inconceivability. Annual Review of Anthropology 2001, [s.l.], v. 30, p. 219-334, 2001.

QUINE, W. O. Word and Object. Cambridge, Massachusetts: MIT Press, 1960.

SCHMITZ, J. Balanced Ecology. Analog. Astounding Science Fiction, [s.l.], p. 31-38, March 1965.

SOUZA, Moisés B. Anfíbios. Reserva Extrativista do Alto Juruá e Parque Nacional da

Serra do Divisor, Acre. Campinas: Editora do Instituto de Filosofia e Ciências Humanas, 2005. (Série Pesquisa e Monitoramento Participativo em Áreas de Conservação Gerenciadas por Populações Tradicionais, vol. 2. Rio Branco: Centro de Ciências Biológicas e da Natureza - Universidade Federal do Acre, Associação dos Seringueiros e Agricultores da Reserva Extrativista do Alto Juruá - ASAREAJ).

TADDEI, Renzo. Meteorologistas e profetas da chuva: conhecimentos, práticas e políticas da atmosfera. São Paulo: Terceiro Nome, 2017.

TSING, Anna L. Viver nas Ruínas: paisagens multiespécies no Antropoceno. Tradução de Thiago Mota Cardoso et al. Brasília, DF: IEB, 2019.

TSING, Ana. The Mushroom at the End of the World: on the possibility of life in capitalist ruins. Princeton: Princeton University Press, 2015.

VASCO-PALACIOS, Aída M. et al. Conocimiento tenoecológico de los hongos entre os indígenas Uitoto, Muinane y Ankoke de la Amazonia Colombiana. Acta Amazonia, [s.l.], v. 38, n. 1, p. 17-30, 2008.

VIVEIROS DE CASTRO, Eduardo. And. Manchester Papers in Social Anthropology, [s.l.], n. 7, 2003.

VIVEIROS DE CASTRO, Eduardo. The Relative Native: essays on Indigenous Conceptual Worlds. Chicago: Hau Books, 2015. 


\section{Mauro W. B. Almeida}

Ph.D. em Antropologia Social (University of Cambridge, Professor do Departamento de Antropologia da Universidade de Campinas.

Endereço profissional: Rua Cora Coralina, n. 100, Cidade Universitária Zeferino Vaz, Barão Geraldo Campinas, São Paulo. CEP: 13083-896.

E-mail: maurowbalmeida@gmail.com

ORCID: https://orcid.org/0000-0001-6612-9593

\section{Como referenciar este artigo:}

ALMEIDA, Mauri W. B. Anarquismo Ontológico e Verdade no Antropoceno. Ilha - Revista de Antropologia, Florianópolis, v. 23, n. 1, p. 10-29, janeiro de 2021. 